\title{
Um Marx de ponta-cabeça: luta de classes, sincronismo e o olhar sobre o(s) outro(s) na obra de Jean Tible
}

\author{
An upside-down Marx: class struggle, synchronism and the look at the \\ other $(s)$ in the work by Jean Tible
}

Kauan Willian dos Santos ${ }^{\mathrm{a}}[$

Resenha de: TIBLE, Jean. Marx Selvagem. São Paulo: Autonomia Literária, 2020, 341p.

Em uma das suas últimas obras, o estudioso Benedict Anderson entrecruza a história da libertação nacional das Filipinas e de Cuba com o desenvolvimento do anarquismo, do socialismo, do republicanismo radical no sul global e de seu nacionalismo, contado através de uma análise histórica e sociológica de escritores da literatura nacional desses países. Para um deles, o filipino Isabelo de Los Reyes, escritor do Iglesia Filipina Independiente, foi imprescindível sua passagem na Espanha, onde, ao seu retorno à Manila, "levava uma pequena biblioteca bastante idiossincrática: Tomás de Aquino e Voltaire, Proudhon e a Bíblia, Darwin e Marx, Kropotkin e Malatesta"(Anderson, 2005, p. 258). Para Anderson, a conexão dos nacionalismos militantes, do iluminismo, de religiões radicais e dos socialismos era possível devido ao período de "globalização incipiente" (ANDERson, 2005, p. 21), onde ideias e experiências eram constantemente interpretadas, interpeladas e reapropriadas de acordo com cada realidade, necessidade e intenção de grupos subalternos.

Essa tradição fez com que grupos e autores indígenas, ou seus observadores, criassem teorias, estudos e movimentos de sincronia entre propostas de libertação e lutas geridas na Europa ocidental e experiências de passado colonial. É por isso que o peruano e marxista latino-americano José Carlos Mariátegui pôde afirmar que "o socialismo, afinal, está na tradição americana. A mais avançada organização comunista primitiva que a história registra é a Inca” (MARIÁTEGUI, 2005, p. 120). Assim, para o pesquisador Michael Löwy, "Mariátegui trabalha a questão indígena como chave do debate marxista latino-americano, rejeitando tanto o excepcionalismo indo-americano quanto o eurocentrismo” (p. 34).

a Doutorando em História Social pelo Programa de Pós-Graduação em História da Faculdade de Filosofia, Letras e Ciências Humanas (FFLCH) da Universidade de São Paulo (USP), bolsista pela Coordenação de Aperfeiçoamento de Pessoal de Nível Superior (CAPES). E-mail: kauanwilliano9@gmail.com 
Homenageando, criticando-o por sua visão por vezes idealizadora das sociedades indígenas peruanas, e tendo como ponto de partida tal sociólogo e ativista político citado, mas além disso, contando com uma incrível tradição indígena que construiu o socialismo global e anticolonial - simbolizado também por Manuel González Prada, um anarcossindicalista peruano que está entre os "primeiros a efetuar uma peruanização de uma ideologia revolucionária européia” (p. 35) - o proeminente estudioso Jean Tible, em sua obra Marx Selvagem, exercita uma reflexão que torna possível uma mediação teórica dos pensamentos e escritos de Karl Marx, com antropólogos estudiosos das sociedades sem (e contra Estados) como Pierre Clastres, e com lutas contemporâneas, como as Yanomami, ou "perspectivismo ameríndio" de Eduardo Viveiros de Castro. Ele dialoga e aproxima-se, assim, de uma possível perspectiva sincrética, que ao mesmo tempo possa descolonizar o pensamento marxista, mutando-o, mas também que as demais lutas também possam absorver a tradição marxiana, o que torna necessário um debate intenso entre vários autores e questões das ciências sociais, da sociologia e da antropologia.

Essa narrativa e intento, para os marxistas, são possíveis a partir da uma “tradição de crítica ativa do materialismo histórico" (MATTos, 2019), que tem como pensadores e militantes Antonio Gramsci, Walter Benjamin, Rosa Luxemburgo, Herbert Marcuse e outros. Com as criticas dessa tradição aos caminhos da União Soviética e seu fim em 1990, autores como Raymond Willians, Edward Thompson, Christopher Hill, e mais recentemente Marcus Rediker, Peter Linebaugh, Antonio Negri, Michael Hardt, Silvia Federici, Michael Löwy, Ruy Braga e outros retomam tal tradição, também influenciados por movimentos, como os das lutas ecológicas, das ações antiglobalização, do operaísmo italiano, e mais tarde, da primavera árabe, das lutas indígenas e territoriais como dos Zapatistas em Chiapas, na Palestina e Rojava no Oriente Médio, e nas recentes lutas de multidões nos protestos de 2013 no Brasil e em outros lugares. Nesse caminho, ao analisar o conceito de classe, Thompson afirmou que ela não é "uma estrutura, nem mesmo uma categoria, mas algo que ocorre efetivamente (e cuja correspondência pode ser demonstrada) nas relações humanas" (Thompson, 1987, p. 9) o que combina perfeitamente com o conceito de materialismo histórico de Benjamin que considera "o mais essencial" não o "materialismo filosófico abstrato", mas "a luta de classes" (p. 109). Ou seja, nessas visões, é rejeitado um marxismo construído apenas por metafísica ou por gabinetes sem relação com as lutas e suas modificações, ou mesmo com visões vanguardistas e elitistas que, com o tempo, podem se descolar das bases. 
$\mathrm{Na}$ antropologia temos autores como Lewis Morgan, em Ancient Society, que construiu uma noção de tentativa de visualização do "outro" que, mesmo, por vezes, impregnado de antropocentrismo e eurocentrismo, foi importante nessa discussão e análise.

É sintomático, portanto, que Jean Tible seja professor do Departamento de Ciência Política da Universidade de São Paulo (USP), mestre pelo Instituto de Relações Internacionais da Pontifícia Universidade Católica do Rio de Janeiro (2005) e doutor em Sociologia pela Universidade Estadual de Campinas (2012), onde defendeu a tese Marx e América Indígena: diálogo a partir dos conceitos de abolição e recusa do Estado, que desembocou em livro publicado pela primeira vez em 2013 pela editora Annablume e re-apresentado agora pela Autonomia Literária. Tible é também co-organizador da obra Junho: potência das ruas e das redes de 2014, Cartografias da emergência: novas lutas no Brasil de 2015, ambas pela Fundação Friedrich Ebert. Ele tem interesse, portanto, não só em estudos e escritos de Marx e do pensamento marxiano clássico, mas também em movimentos e autores recentes e complexos que desafiam o materialismo histórico e a sua dialética. Para Tible, então, quando "pensamos Marx a partir das lutas, [...] o universal (ou melhor, o comum) passa a não ser mais dado, mas sim a construir coletivamente, pela conexão das múltiplas lutas” (p. 28).

O seu livro presente está dividido em três capítulos. O primeiro "Marx, Engels e os 'Outros': uma leitura dos seus escritos que vão além da Europa Ocidental”, Tible lança luz primeiramente para análises marxistas e suas influências pelo prisma de progressão e universalização da história que, ao se aterem às etapas da história universal e considerarem o avanço do capitalismo como algo imprescindível para o socialismo, julgaram muitas sociedades originárias e colonizadas como retrógradas e reacionárias. Nesse sentido, faltou ao autor exemplificar frases e constatações de Marx que, por exemplo, sobre a Índia, afirmou que a Inglaterra traria às civilizações "semibárbaras, semicivilizadas, ao destruir sua base econômica, [...], a única revolução social que já se viu na Ásia” (SAmIs, 2011, p. 110). Não obstante, Tible indica que Marx e Engels (mais o primeiro do que o segundo) mudam suas posições a partir do aprofundamento da crítica a Hegel e ao idealismo alemão, da construção do materialismo histórico dialético prático como na Primeira Internacional dos Trabalhadores, e teórico, através da construção da obra $O$ Capital e da análise da xenofobia, escravidão e lutas anticoloniais, do caso russo e de suas colônias rurais e da experiência da Comuna de Paris. O autor indica que, assim, Marx e Engels podiam ver formas diferentes em que o capitalismo se desenvolveu e se empregou em diversos campos, usando resquícios coloniais, 
e que formas diferentes de resistência e da classe poderiam surgir, o que construiria uma tradição de análise anticolonial contida em militantes e líderes como Lênin. Assim, “ambos apoiam os chineses na segunda guerra do ópio, [...] Engels também muda de opinião no que toca à Argélia, elogiando a resistência de árabes e kabyles e condenando a barbárie francesa" (p. 66). E no tocante às formas de organização comunais da Rússia, elas poderão "servir de ponto de partida para um desenvolvimento comunista" de modo "que uma complemente a outra" (p. 67), o que faz com que a tomada de um Estado, contida na primeira edição do Manifesto do Partido Comunista, seja revista, incluindo formas de sociedade antiestatistas contra o capitalismo global.

Após isso, em “Marx e Clastres contra o Estado", Tible analisa as concepções antiestatistas de Karl Marx e de Pierre de Clastres através do pensamento político do primeiro e da antropologia política do segundo, buscando uma conexão dos dois pensamentos, sem transformá-los necessariamente. $\mathrm{O}$ autor considera que tanto no decorrer de suas considerações sobre a superação da história e das dominações contra o operariado, mas também a partir dos contatos com outras formas organizacionais sem Estado, "Marx e Engels criticam os que se atêm às lutas no interior do Estado" e reafirmam a luta proletária contra o Estado; estes têm de suprassumir sua própria condição de existência anterior, isto é, o trabalho, e por isso, em oposição ao Estado, a forma pela qual os indivíduos se deram, até então" (p. 136). Já, para Clastres, é analisado o caráter quase primário em seu estudo de não atribuir a inexistência do Estado como algo que sugere certo grau civilizatório. Ao contrário, sociedades ameríndias não fazem distinção entre o grau de natureza e cultura ou de política e natureza já que "tais abordagens privilegiam o conceito de naturezas-culturas”. Clastres critica os marxistas e sua visão de Estado exatamente por esse motivo, o que é justificado por Tible. Para este último, de fato, tais posições existem, mas não considera uma tradição antiestatista e libertária de Marx e de marxistas como Rosa Luxemburgo e Walter Benjamin.

É nesse capítulo que existe um debate que para nós é bastante importante. Tible considera que embora Marx chegue a posições antiestatistas, elas se diferenciam da visão de Bakunin, portanto a divisão entre marxistas e anarquistas permanece. Nesse sentido, para o russo Mikhail Bakunin, o Estado é um tipo de dominação e coerção em si, o que difere de Karl Marx onde reconhecia que o Estado era uma forma política e administrativa em relação a certo sistema social e econômico, o capitalismo. É por isso que para Tible, Marx sugere meios de transição que seria “o autogoverno das comunidades" (p. 187). Com isso, podemos dar algumas sugestões: Marx não entendeu a teoria política de Bakunin, o que Tible, 
por ler o anarquista nas lentes de Marx e Engels endossa, ou Marx entendia muito bem Bakunin, mas por questões de disputa política usou espantalhos falsos, o que acaba comprometendo a análise de Tible. Dizemos isso porque a bibliografia recente sobre os estudos de Bakunin e do anarquismo na Primeira Internacional, inclusive de muitos marxistas (ANDERSON, 2005; OlIVIER, LöwY; 2016), não considera a visão de Bakunin e seu órgão político, a Aliança da Democracia Socialista, como uma estratégia vazia que sugere que o Estado vai desaparecer sem alguma mediação ou forma transitória. É exatamente a forma da comuna, as organizações de resistência como o sindicalismo - por isso Bakunin construía também e defendia a Internacional dos Trabalhadores - e as diversas formas organizacionais contra e sem Estado que são defendidas pelo russo e os aliancistas. É certo que o Estado podia ser uma esfera de dominação mesmo sem existir capitalismo, já que anarquistas enxergam que as dominações podem ter rumos diferentes, mas isso significa que tais dominações não estão ligados a uma base material. Por isso, Bakunin sugere a "completa emancipação econômica do trabalhador", e, nesse sentido, a AIT "é a organização que deve protagonizar a revolução social e fornecer as bases para a construção do socialismo coletivista-federalista” (CôRREA, 2019, p. 428). Do mesmo modo, Bakunin constrói a Comuna de Lyon e apoia a Comuna de Paris também, já que "toda comuna têm o direito absoluto de ser livre, autônoma, de viver e governar-se segundo seus interesses e suas necessidades particulares" (CôRreA, 2019, p. 441). Sem nos alongar, deixamos aqui alguns indícios para os interessados em estudos socialistas antiestatistas considerarem leituras mais aprofundadas de uma ideologia que já tem mais de um século e meio lutando contra o Estado e, deveras, contra o capitalismo. E se a crítica ativa do materialismo histórico queria fazer essa ponte, a tradição socialista libertária apresenta uma prática anticolonial, decolonial, descentralista, insurrecional e autonomista em suas bases (ANDERSON, 2005).

Por fim, no terceiro capítulo, "Cosmopolíticas", o autor, a partir de discursos e práticas dos Yanomami, grupo de aproximadamente 35.0oo indígenas que vivem em mais de 200 aldeias na floresta amazônica, na fronteira entre Venezuela e Brasil, e do perspectivismo de Viveiros de Castro, antropólogo brasileiro estudioso de sociedades indígenas, sugere uma ponta ou diálogo com as visões de Karl Marx sobre sociedades que podem se utilizar de modos organizativos sem (e contra) o Estado para a superação revolucionária do Estado nacional e do capitalismo. Nesse sentido, um dos mais interessantes ensinamentos e colocações dos Yanomami e de outros povos observados por Viveiros de Castro é a não diferenciação entre natureza e sociedade, a partir de uma relação mútua e social, assim como a perspectiva 
de alteridade e multiplicidade, que faz com que "enquanto na ótica ocidental, tem por objetivo compartilhar a semelhança - presentes no conceito de fraternidade - no mundo indígena, a relação se dá por causa das diferenças.” Tal perspectiva se assemelha à de Marx, que em certos escritos considera, na realidade, a totalidade, como uma "ontologia da relação" ou "multiplicidade das relações." (p. 283)

Tudo isso faz com que Marx Selvagem apresente pensamentos e uma história de ponta cabeça (HıLl, 1987), no qual, de fato, nos sentimos diferentes e refletimos a partir dessa alteridade para uma reflexão necessária, quando diversos movimentos, organizações políticas e projetos, muitas vezes, não correspondem mais aos anseios de diversos grupos oprimidos ao redor do globo. Devemos lembrar que Benedict Anderson afirmava seu interesse pelo estudo dos nacionalismos e Estados devido à perturbadora guerra entre o Vietnã, o Camboja e a China no fim do século XX (ANDERSON, 1989, p. 9), o que mostrava que a ideologia nacionalista e estatista superava, mesmo nos próprios países ditos socialistas, o internacionalismo e a consciência de classe. Um retorno a um Marx selvagem, mas não só, de todos os ditos "selvagens" e "rebeldes" contra tais dominações, é inevitável e necessário.

\section{REFERÊNCIAS}

Anderson, Benedict. Anarquismo e imaginação anticolonial. Campinas: Editora da Unicamp, 2005.

ANDERSOn, Benedict. Nação e consciência nacional. São Paulo: Editora Ática, 1989.

Côrrea, Felipe. Liberdade ou morte: teoria e prática de Mikhail Bakunin. São Paulo: Editora Faísca, 2020.

HILL, Christopher. O mundo de ponta cabeça: ideias radicais durante a revolução inglesa. São Paulo: Companhia das letras, 1991.

Mariátegui, José Carlos. Por um socialismo indo-americano: ensaios escolhidos. Rio de Janeiro: Editora UFRJ, 2005.

Mattos, Marcelo Badaró. A classe trabalhadora: de Marx ao nosso tempo. São Paulo: Boitempo, 2019.

SAmis, Alexandre. Negras tormentas: o federalismo e o internacionalismo na Comuna de Paris. São Paulo: Hedra, 2011.

OLIVIER, Besancenot; Löwy, Michael. Afinidades revolucionárias: por uma solidariedade entre marxistas e libertários. São Paulo: Unesp, 2019.

Thompson, Edward. A formação da classe operária inglesa: a árvore da liberdade. Rio de Janeiro: Paz e Terra, 1987.

Recebido: 18/07/2020 | Aprovado: 13/02/2021 